\title{
O Ensino de Ciências em Escolas UCA: Uma Análise das Estratégias de Mediação Didática
}

\author{
Cícero Bandeira Lima Filho ${ }^{1}$, José Aires de Castro Filho ${ }^{1}$, Arliene Santisteban \\ Campos $^{2}$ \\ ${ }^{1}$ Universidade Federal do Ceará (UFC). Campus do Pici, bloco $9011^{\circ}$ andar, \\ CEP: $60.455-760$ \\ ${ }^{2}$ Secretaria da Educação Básica / Escola Anísio Teixeira. Rua Rio Grande do Sul \\ $\mathrm{n}^{\circ}$ 680. CEP: $60.440-805$ \\ cicerobandeira@yahoo.com.br, aires@virtual.ufc.br, \\ lienesantisteban@gmail.com
}

\begin{abstract}
This work aimed to reflect on the use of laptop education in schools covered by the Programa Um Computador por Aluno (UCA). Considering that one of the central proposals of the Institute is to adopt methodologies that favor the emergence of collaborative practices between teachers and students, we analyze lesson plans produced in schools participating in the program and made available in website called Portal do Professor, in order to ascertain how the laptop is being used and from which mediation strategies. The research is qualitative and turned to study of natural science as school content, elementary school II. The results of this analysis are presented below.
\end{abstract}

Resumo: Este trabalho teve como propósito refletir sobre a utilização do laptop educacional em escolas contempladas pelo Programa Um Computador por Aluno (UCA). Considerando que uma das propostas centrais do UCA é a adoção de metodologias que favoreçam o surgimento de práticas colaborativas entre alunos e professores, analisamos planos de aula produzidos em escolas participantes do programa e disponibilizadas no Portal do Professor, a fim de verificar como o laptop está sendo utilizado e partir de quais estratégias de mediação. A pesquisa tem caráter qualitativo e voltou-se para a disciplina ciências naturais, do ensino fundamental II. OS resultados desta análise serão apresentados a seguir.

\section{Introdução}

A observação do cotidiano das salas de aulas e a leitura de documentos oficiais como os Parâmetros Curriculares Nacionais - PCN (1999) indicam que a organização das situações didáticas privilegiam a utilização de estratégias baseadas na transmissão/recepção de conteúdos. De acordo com as Orientações Complementares aos Parâmetros Curriculares Nacionais ( $\mathrm{PCN}+)$ Ensino Médio, o fazer pedagógico ainda é caracterizado pela "didática da transmissão"; "pedagogia do discurso"; pela 
"transmissão desprovida de contexto" e "resolução de exercícios padronizados". [Brasil, 2002].

A situação descrita acima pode estar na raiz dos problemas de aprendizagem observados atualmente, já que contribui para o desenvolvimento de atitudes passivas que não despertam a curiosidade e o gosto pelo aprender, provocando, desinteresse e apatia, impedindo o surgimento de uma postura ativa, reflexiva e autônoma por parte dos estudantes frente aos objetos do conhecimento.

Se tratarmos especificamente do ensino de ciências, identifica-se crescente desinteresse dos estudantes por esta área do conhecimento [Cachapuz 2010] [Pozo 2009]. Dentre os fatores que contribuem para esta situação, Pozo (2009) destaca os seguintes: ensino baseado na realização de atividades individualizadas e não a cooperação; dificuldade dos alunos em interpretar e dar sentido às informações e ensino voltado apenas para transmissão de conteúdos conceituais.

No intuito de contribuir para melhorar o cenário apresentado anteriormente, diversas experiências e estudos, voltados para diferentes áreas do conhecimento, têm analisado o potencial das Tecnologias da Informação e Comunicação (TIC) para contribuir com a educação escolar.

Conforme foi citado anteriormente, diversos estudos se debruçaram sobre a perspectiva de identificar contribuições da utilização das TIC para a educação. Citaremos, a seguir, alguns destes e seus respectivos resultados.

No âmbito da Universidade Federal do Ceará (UFC), o Grupo de Pesquisa e Produção de Ambientes Interativos (PROATIVA), iniciado em 2001, desenvolve Objetos de Aprendizagem (OA), que são "atividades multimídia, interativas, na forma de animações e simulações que têm a idéia de quebrar o conteúdo educacional disciplinar em pequenos trechos que podem ser reutilizados em vários ambientes de aprendizagem". 1

Estudo realizado através da aplicação do OA Pato quântico indica que houve contribuições à aprendizagem de Física. Segundo Sales (2008), “a interação dos estudantes com o software resultou em uma aprendizagem significativa do fenômeno efeito fotoelétrico, com eficiente transposição didática dos conteúdos e o fortalecimento de mudanças conceituais".

Referindo-se a utilização de ambientes de autoria num contexto de sala de aula, Shäffer, Sperb e Fagundes (2011) apontam "resultados mais efetivos em relação à construção do conhecimento e ao desenvolvimento conceitual do aluno quando há mudanças pedagógicas em sala de aula".

Em recente trabalho de pesquisa voltado para o contexto do programa Um Computador por Aluno (UCA), Nascimento et al, (2011) cita como melhorias proporcionadas pelo UCA, "aumento da quantidade de aulas com recursos digitais; aulas de campo; trabalho com projetos e atenção à interdisciplinaridade".

Consideramos relevante ressaltar, que a implantação das TIC nas escolas devem estar associadas a mudanças nas práticas docentes para romper com modelos tradicionais, ainda muito presentes. É necessário, portanto, adotar metodologias que

\footnotetext{
${ }^{1}$ Fonte: www.proativa.vdl.ufc.br
} 
promovam maior participação, envolvimento e interação entre os participantes, já que não basta inserir computadores no ambiente de sala de aula. Em muitos casos, estes equipamentos são subutilizados, desperdiçados e os resultados observados não justificam os elevados investimentos financeiros. Outras vezes, são apenas incorporados ao cotidiano da escola, adaptando-se às práticas predominantes, reforçando o jeito de ser da escola, o que impede que os instrumentos tecnológicos tenham usos mais criativos [Sancho 2006], [Papert 2008], [Kenski 2007].

A pesquisa que desenvolvemos teve como foco o Programa UCA, uma das mais recentes políticas do Governo Brasileiro, direcionada para implantação das TIC na educação. As escolas contempladas por este programa receberam um número de laptops equivalente à quantidade total de alunos matriculados.

As concepções pedagógicas do UCA enfatizam a necessidade de adotar "novas metodologias educacionais", de desenvolver estratégias que incentivem a "formação de comunidades de aprendizagem", pois considera que estas favorecem a expressão, troca de ideias e a mediação compartilhada que propicia a reflexão e o aprofundamento dos saberes, com consequente melhoria nas atividades que estudantes e educadores desenvolvem [Brasil 2007]

As reflexões realizadas até aqui nos colocaram diante dos questionamentos centrais desta investigação, a saber: em que medida a proposta de adotar metodologias que favoreçam a colaboração, de grande importância para o sucesso do UCA, está se realizando? Como o laptop está sendo utilizado pelos professores? Estão conseguindo diversificar as metodologias empregadas? As estratégias de mediação didáticas propostas favorecem o surgimento de ações colaborativas? O laptop tem sido relevante para viabilizar a realização das atividades propostas?

Tivemos como propósito analisar as estratégias planejadas por professores de ciências de escolas participantes do UCA, buscando identificar se estas promovem situações didáticas, que predominem ações colaborativas entre professores e alunos e entre alunos entre si. Esse foco ampara-se nas concepções fundamentais do Programa que destaca a colaboração como um princípio relevante para o sucesso dos objetivos propostos. A seguir descreveremos os procedimentos adotados para realização.

\section{Metodologia}

Este trabalho tem caráter qualitativo e buscou refletir sobre as questões norteadoras apresentadas anteriormente, através da análise de planos de aula, disponíveis no Portal do Professor, que tenham sido elaborados por professores de escolas contempladas pelo programa UCA. Pretendemos identificar as estratégias didáticas previstas nos planos de aula e os recursos escolhidos para viabilizar sua consecução.

O Portal do Professor é um repositório, criado pelo MEC, para disponibilizar materiais educacionais: planos de aula, de diversas áreas do conhecimento; conteúdos multimídia, como vídeos e áudio; objetos de aprendizagem e aplicativos diversos, além de materiais para estudos sobre diferentes temas relacionados a educação ${ }^{2}$.

A escolha de escolas contempladas pelo programa UCA se deu em função de entendermos que o fato de dispor laptop conectado à internet amplia os recursos

\footnotetext{
${ }^{2}$ http://portaldoprofessor.mec.gov.br
} 
disponíveis ao professor o que pode contribuir tanto no planejamento das aulas quanto sua realização.

A fim de delimitar o universo de análise, teremos como foco a área de ciências da natureza, no ensino fundamental II. Até 22/jun/2012, numa consulta ao referido portal encontramos 121 aulas de ciências do ensino fundamental II, planejadas em escolas e universidades. Em busca de realizar um recorte que nos permita estabelecer um universo menor para análise, definimos como critérios de seleção: priorizar aulas planejadas por escolas UCA; optamos por aquelas voltadas para temas relacionados à Biologia e excluimos aulas que abordem temas similares. Chegamos então a um universo de 26 planos de aula a serem analisados, dos quais trataremos adiante.

Destas 26, decidimos realizar uma análise mais minuciosa em 3 planos de aula. Foram escolhidas aquelas com maior número de acesso, tomando como referência a data 22/junho/2012. São elas: "Seres vertebrados e invertebrados: como diferenciá-los", com 8886 acessos; "Poluição do Solo: quais as conseqüências?", com 2556 acessos e "O que é Eritroblastose fetal", com 2536 acessos.

A quantidade de acessos não se constitui, necessariamente, um indicador de qualidade da aula, mas nos leva a pressupor que despertou maior interesse nos professores, o que pode ter possibilitado maior replicação das estratégias previstas nestas aulas. Teve, portanto, maior alcance. Já que o Portal do Professor tem como objetivo socializar práticas realizadas em sala de aula, consideramos relevante analisar as aulas que mais atraíram a atenção dos docentes.

A análise dos dados foi realizada a partir da definição de três categorias de análise, escolhidas de acordo com o enfoque aqui adotado. Tratamos inicialmente da atuação do professor e das estratégias didáticas previstas para incentivar ações colaborativas entre os envolvidos; procuramos identificar qual é a postura que o aluno deverá ter nas atividades pensadas pelo professor: ele será autor ou receptor? E por fim, procuramos identificar indícios que apontem se a utilização do laptop educacional é, ou não, relevante para realização das diversas atividades previstas.

Quando se trata de definir o que é relevante para constar numa aula de qualidade, certamente há outros aspectos poderiam ser considerados, entretanto pelas características deste trabalho circunscrevemos nossa atuação a estes critérios.

\section{Fundamentação Teórica}

Este trabalho tem como base as contribuições da Psicologia Sócio-Histórica de Vygotsky (2007), a mediação didática abordada por D'Ávila (2008) e os estudos recentes sobre interação e mediações em sala de aula de Colaço (2007;2010).

Estes estudos nos fornecerão as referências para as análises sobre a ação docente em sala de aula, buscando identificar se as mesmas contribuem para estimular ações colaborativas entre estudantes e destes com o professor, o que segundo os referenciais que nos baseamos são essenciais para que a aprendizagem ocorra.

Nessa perspectiva, ao estabelecer interações com as ferramentas e com membros da sua cultura, constrói saberes que interferem sobre seus modos de vida e muda sua relação com o conhecimento. Segundo Vygotsky (2007), "todas as funções no desenvolvimento da criança aparecem duas vezes: primeiro no nível social, e, depois, no nível individual; primeiro entre pessoas (interpsicológica), e, depois, no interior da criança (intrapsicológica)". 
Através da interação com instrumentos da realidade (concretos ou simbólicos) os seres humanos utilizam-se de estratégias de mediação para controlar seu próprio comportamento. O exemplo clássico de mudar o anel de um dedo para outro a fim de lembrar-se de um compromisso evidencia essa relação, na medida em que procura estabelecer um elo entre um objeto concreto e o pensamento. Corroborando com os pressupostos do autor, Brunner (2008 apud VYGOTSKY, p. IX) afirma que "o homem, por assim dizer, é modelado pelos instrumentos e ferramentas que usa, e nem a mente nem a mão podem, isoladamente, realizar muito".

O estudo que propomos é voltado para a educação escolar, especificamente para o ambiente de sala de aula. De acordo com Colaço (2010), a escola é um espaço singular para a construção do conhecimento científico, entretanto é necessário organizar as situações didáticas de maneira a favorecer a construção destes saberes, que se dá principalmente a partir de atividades compartilhadas e da possibilidade efetiva de trocas.

Ainda enfatizando o ambiente formal de escolarização destacamos a relevância das ações docentes para este processo. Segundo Colaço (2010), "a atuação do professor na promoção de atividades compartilhadas é decisiva para que elas tenham repercussão na relação ensino-aprendizagem que acontece na educação escolar”.

A atividade do professor é baseada numa série de situações que o mesmo prepara para tornar possível, ao aluno, a aprendizagem. Para tornar viáveis os seus objetivos, o professor se mune de diversas estratégias. Colaço (2007), compreende como estratégias de mediação, "o modo como as pessoas utilizam meios (instrumentais ou simbólicos) para intermediar suas atividades, as quais envolvem interação com o outro e com o mundo".

$\mathrm{Na}$ perspectiva de D'Avila (2008) o conceito de mediação refere-se a "intercessão ou intermédio" e acrescenta: "significa o que está entre duas partes e estabelece uma relação entre elas". Afirma, ainda, que a mediação didática "consiste em estabelecer as condições ideais para que a aprendizagem ocorra" (Ibid).

As estratégias utilizadas pela pedagogia tradicional se tornaram obstáculos à aprendizagem, na medida em que não leva em conta elementos essenciais a este processo. Segundo D'Avila (2008), "a busca do conhecimento corresponde às necessidades da vida social, evocando, assim, as relações interpessoais; logo um aluno aprenderá mais e melhor se estiver na companhia solidária de outros".

Dos vários autores, podemos depreender que a tecnologia, em si, não pode promover uma prática enriquecedora, ao contrário seu uso é definido na implementação destas práticas, nas maneiras como estes artefatos são utilizados. Esta formulação nos remete às questões centrais deste trabalho, que busca analisar as estratégias propostas pelos professores de escolas UCA ao planejarem suas aulas, pois elas são serão decisivas para determinar a efetividade das contribuições do uso de ferramentas computacionais para educação formal. Desta forma atestamos a validade e consistência teórica deste trabalho.

\section{Análise e Interpretação dos dados}

Para tornar possível a obtenção de respostas que esclareçam, ainda que parcialmente, as questões norteadoras deste trabalho, identificamos e elencamos as principais estratégias didáticas planejadas. Em função da natureza deste ensaio, optamos 
por dar ênfase àquelas que aparecem reiteradamente. Das 25, identificadas, apresentamos apenas 11 , na tabela 01 .

Aqui nos deparamos com um dos primeiros achados do trabalho: a quantidade e a diversidade de estratégias previstas, o que indica certa disposição em alterar o modelo tradicional, de caráter expositivo, comentado na introdução deste trabalho.

Tabela 1. Estratégias didáticas previstas e quantidade de vezes que foram citadas

\begin{tabular}{|l|l|c|}
\hline & Estratégia didática & Quantidade citadas \\
\hline 1. & $\begin{array}{l}\text { Discussão (em sala ou em grupo)/debate/socialização } \\
\text { /iálogo/Exposição dialogada. }\end{array}$ & 29 \\
\hline 2. & Apresentação de audio e/ou vídeos & 25 \\
\hline 3. & Leitura de texto (web ou editor de texto) & 17 \\
\hline 4. & Resolução de questionário & 10 \\
\hline 5. & Consulta de temas em sites/internet & 9 \\
\hline 6. & Elaboração e apresentação de slides & 7 \\
\hline 7. & Ilustração através de imagens & 6 \\
\hline 8. & Consulta em dicionário on-line & 6 \\
\hline 9. & Realização de experimento & 5 \\
\hline 10. & $\begin{array}{l}\text { Organização e exposição de informações em tabelas e } \\
\text { gráficos }\end{array}$ & 6 \\
\hline 11. & Utilização de história em quadrinhos, charges e tirinhas & 21 \\
\hline
\end{tabular}

Das estratégias identificadas acima constatamos que elas podem ser agrupadas a partir das categorias definidas neste trabalho. Em $51 \%$ das estratégias didáticas planejadas havia a previsão de atividades colaborativas. Também em $51 \%$ das estratégias os alunos deveriam desempenhar ações, ter uma postura ativa diante do objeto do conhecimento.Todas as estratégias planejadas pretendiam utilizar o laptop de alguma maneira. No gráfico a seguir apresentamos os percentuais em que se manifestam.

Figura 1: Estratégias didáticas previstas nos planos de aula do Portal do Professor

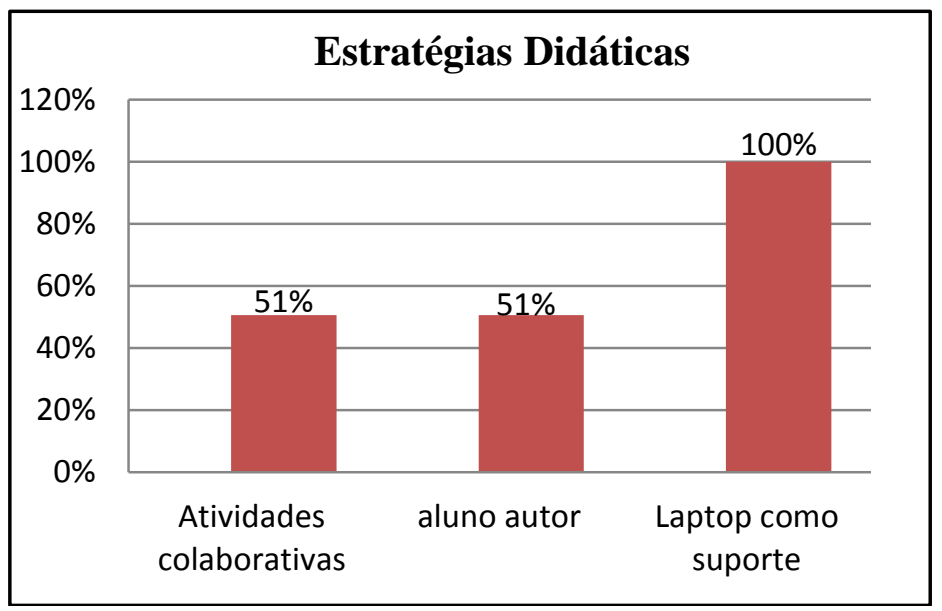

Fonte: Coleta direta 


\subsection{A Atuação do professor e as estratégias colaborativas}

Destacamos, com mais detalhes, algumas das atividades apresentadas na tabela 01. São elas: discussão em pequenos grupos; consultas do significado de termos desconhecidos, com posterior socialização; montagem e socialização de apresentação de slides para os demais alunos da sala, criada a partir de temática explorada pelo professor; discussão, fomentada a partir da exposição de vídeos; realização de experimentos e posterior discussão sobre os resultados observados; observação do campo, registro e posterior discussão.

A utilização de recursos, como vídeos, associados a discussões posteriores é uma maneira de enriquecer seu potencial educacional e ir além da uma exposição áudiovisual. Destacamos, nestes momentos, a atuação do professor que propõe questões para nortear o diálogo e intervém de acordo com a necessidade, inclusive para esclarecer erros conceituais.

As situações didáticas organizadas em pequenos grupos são espaços propícios ao surgimento de interações que favoreçam o processo de aprendizagem. Constatamos que, em diversos momentos, são propostos trabalhos em grupo entre os alunos. Para que se tornem efetivas quanto à promoção de novos aprendizados, é necessário levar em conta que não basta ser uma atividade coletiva, é necessário que haja trocas entre seus os membros, valorizando a participação de cada um, e estimulando o compartilhamento de dúvidas e saberes. [Colaço, 2010].

A atuação do professor ganha ênfase como mediador das situações didáticas, seja apresentando questões para debate, fazendo perguntas, motivando para participação ou fornecendo orientações sobre como proceder. Segundo Shimamoto (2012):

Cabe ao/a professor/a observar a capacidade de argumentação dos/as
alunos/as, a maneira como cada um expõe suas ideias, defende os seus
argumentos e discute com os colegas de sala. Além disso, ele/a deve ficar
atento com possíveis equívocos conceituais, interferindo imediatamente no
sentido de posicionar os/as alunos/as a pensarem nos conceitos mais
adequados.

\subsection{Postura do aluno: autor ou receptor?}

As diversas situações didáticas propostas colocam o aluno em posições variadas. Em algumas delas ainda verificamos que o aluno é visto na perspectiva de receber as informações, seja através do professor, ou através de algum recurso do laptop, como a internet. Constatamos isso no expressivo número de atividades apenas de leituras e resolução de exercícios.

Outras situações didáticas prevêem que o aluno tenha funções mais ativas, realizando atividades diversas. Ao ter que selecionar imagens ou elaborar apresentações de slides o aluno estará exercitando sua capacidade de criar. Quando propõe soluções para questões cotidianas, como quando elabora um diário alimentar, levando em conta a quantidade de proteínas ou amido e relaciona o consumo de alimentos aos níveis de colesterol recomendados para se manter saudável, aproxima os saberes da escola ao seu universo particular.

\footnotetext{
${ }^{3}$ Fonte: http://portaldoprofessor.mec.gov.br/fichaTecnicaAula.html?aula=33441
} 
Nas atividades de campo ou de laboratório, os estudantes observam, realizam, testam, experimentam e analisam resultados. São situações privilegiadas, em que é possível associar uma postura ativa e, ao mesmo tempo, reflexiva.

\subsection{Contribuições do Laptop Educacional}

O laptop, utilizado no contexto escolar, adquiriu caráter de suporte para realização das diversas atividades, em sala de aula ou fora dela. Desde a consulta de informações, leitura de textos e imagens, até a elaboração de tabelas, gráficos, slides, produção de áudio e mapas conceituais, o computador tornou possível a realização destas tarefas. Mesmo na realização de experimentos no laboratório de ciências e atividades de campo, o laptop foi utilizado para registrar através fotos e filmagens, os resultados das observações e análises.

A aula sobre seres vertebrados e invertebrados, citada anteriormente, é um exemplo de como o laptop pode ser integrado, tanto ao ambiente de sala de aula, quanto a atividades extramuros. Na referida aula, as informações coletadas na internet são organizadas numa tabela de classificação dos seres vivos. Complementando, são utilizados vídeos e por fim, atividade de campo, em que exemplares destes seres que fazem parte do ambiente observado, são fotografados e filmados.

Esta constatação nos remete a refletirmos que o acesso ao conhecimento científico, se dará em grande parte das vezes, mediado por um instrumento tecnológico e que isto tem implicações sobre as práticas docentes e discentes. Os novos instrumentos têm suportes e linguagem diferentes. Estas e outras especificidades irão exigir dos seus utilizadores posturas condizentes.

\subsection{Outras considerações}

Também encontramos referências a ações interdisciplinares. Na aula "Poluição do solo: Quais as conseqüências?"4 é proposto a realização de atividades que integram áreas como: geografia (serão apresentados dados estatísticos sobre a poluição nas cidades), matemática (interpretação de gráficos e tabelas), história (desenvolvimento industrial e suas conseqüências para o meio ambiente e artes (trabalho com imagens, colagem e exposição dos materiais produzidos pelos alunos).

\section{Considerações Finais}

Uma das principais características do ensino tradicional é a centralidade no professor, que atua como fonte, da qual as informações são distribuídas. Opondo-se a esta postura e frente ao novo cenário onde as TIC se fazem presentes, espera-se que o professor desempenhe outros papeis: que atue como organizador das situações didáticas, selecionando dentre a enorme variedade de recursos possíveis aqueles que sejam os mais adequados a situações didáticas específicas.

Os planejamentos de aula disponibilizados no Portal do Professor que analisamos e a variedade de recursos e estratégias adotadas indicam essa tendência: a diversificação na abordagem dos conteúdos das disciplinas. Das 26 aulas analisadas, identificamos 25 estratégias diferentes. Esta diversidade é um aspecto importante na

\footnotetext{
${ }^{4}$ Fonte: http://portaldoprofessor.mec.gov.br/fichaTecnicaAula.html?aula=36551
} 
medida em que explora os conteúdos estudados a partir de perspectivas diferentes, possibilitando ao aluno analisá-los sob diferentes ângulos.

Diversas atividades planejadas propunham que aluno desenvolvesse ações: elaboração e apresentação dos slides, realização de experimentos, confecção de tabelas, e gráficos, dentre outras. Essa perspectiva retira o aluno da condição de mero expectador, conferindo-lhe papel mais ativo. Algumas situações requerem que ele exercite a autoria, outras proporcionam momentos de reflexões e discussões.

O fato de constar no planejamento do professor, diversas atividades coletivas não garante que estas proporcionarão momentos de colaboração, de situações didáticas que possibilitem compartilhamento de significados, negociação de pontos de vista e troca de entendimentos sobre saberes e percursos a serem adotados, entretanto é um indicio consistente, que demonstra que os docentes estão percebendo a relevância de incentivar a adoção de práticas colaborativas no contexto de sala de aula.

Observamos que a utilização do laptop educacional foi prevista, em maior ou menor medida, em todas as estratégias previstas. Ou como suporte ou para registro das atividades. Isto implica dizer o que uso do laptop em si não garante usos inovadores e criativos. Ele pode também ser utilizado dentro uma perspectiva tradicional de educação, o que requer reflexão do professor sobre quais as maneiras que melhor podem aproveitar o potencial destes recursos.

A ação do professor continua sendo de grande relevância, cabendo a ele acompanhar as situações didáticas, seja em pequenos grupos e ou nos momentos de socialização com a sala inteira, fomentando o debate, a troca de ideias, dúvidas e entendimentos entre os diversos participantes, a fim de que as diversas formas de interação previstas não fiquem apenas nos planos de aula, ao contrário, ocorram efetivamente no cotidiano das salas de aula.

\section{Referências}

ALMEIDA, M. E.B, Caixas de Ferramentas em Logo in VALENTE, J.A. O professor no ambiente Logo: formação e atuação. SP: UNICAMP/NIED, 1996.

BRASIL. Secretaria da Educação a Distância. Princípios orientadores para o uso pedagógico do laptop educacional na educação escolar. Brasília: MEC/SEED, 2007.

Secretaria da Educação Média e Tecnológica. PCN + Ensino Médio: Orientações Educacionais complementares aos Parâmetros Curriculares Nacionais. Brasília: MEC/SEMTEC, 2002.

Secretaria da Educação Média e Tecnológica. Parâmetros Curriculares Nacionais: Ensino Médio. Brasília: MEC/SEF, 1999.

CACHAPUZ, A. A Necessária Renovação do Ensino de Ciências. São Paulo: Cortez, 2011.

COLAÇO, V. Inter(ação) Social nos Contextos de Pesquisa/Intervenção em Escolas de Fortaleza. Psicol. estud., Mar 2010, vol.15, no.1, p.127-135. ISSN 1413-7372. http://dx.doi.org/10.1590/S1413-73722010000100014. 
Estratégias de mediação em situação de interação entre crianças em sala de aula. Estud. psicol. (Natal) [online]. 2007, vol.12, n.1, pp. 47-56. ISSN 1413-294X. http://dx.doi.org/10.1590/S1413-294X2007000100006.

D'ÁVILA, Cristina Maria. Decifra-me ou te devorarei: o que pode o professor frente ao livro didático? Salvador: EDUNEB; EDUFBA, 2008.

KENSKI, V. M. Educação e Tecnologias: o novo ritmo da informação. Campinas: Papirus, 2007.

PAPERT, Seymour. A máquina das crianças: repensando a escola na era da informática. Porto Alegre: Artmed, 2008.

POZO, J. A aprendizagem e o ensino de ciências: do conhecimento cotidiano ao conhecimento científico. Porto Alegre: Artmed, 2009.

SANCHO, Juana Maria. Tecnologias para transformar a educação. Porto Alegre: Artmed, 2006.

SALES, G. L. Atividade de modelagem exploratória aplicada ao ensino de física moderna com a utilização do objeto de aprendizagem pato quântico. Revista Brasileira do Ensino de Física. v. 30, n. 3, 3501 (2008).

SHÄFFER, P.B; SPERB, B.F; FAGUNDES, L.C. Squeak Etoys na modalidade 1 para 1: programação e autoria multimídia no desenvolvimento da conceituação. SIMPÓSIO BRASILEIRO DE INFORMÁTICA NA EDUCAÇÃO. 22., 2011, Aracaju. Anais.... p. 1226-1235.

SHIMAMOTO, D. F. Anfibios e sua tranformação. Disponível em http://portaldoprofessor.mec.gov.br/fichaTecnicaAula.html?aula=33441. Acesso em 22/jun/2012.

NASCIMENTO, K.A.S et al. Programa UCA no Estado do Ceará: caminhne percorridos: lições aprendidas. SIMPÓSIO BRASILEIRO DE INFORMÁTICA EDUCAÇÃO. 22., 2011, Aracaju. Anais...p. 1207 - 1215.

UNTALER, L.O. Seres vertebrados ou invertebrados: como diferenciá-los? UCA. Disponível: http://portaldoprofessor.mec.gov.br/fichaTecnicaAula.html?aula=37333. Acesso em 22/jun/2012.

VYGOTSKY. Lev Semenovich. A formação social da mente: o desenvolvimento dos processos psicológicos superiores. $7^{\mathrm{a}}$ ed. São Paulo: Martins Fontes, 2007. 